\title{
Quality of Life and Radiation-induced Late Toxicity Following Intensity-modulated Versus Three-dimensional Conformal Radiotherapy for Patients with Spinal Bone Metastases: Results of a Randomized Trial
}

\author{
TANJA SPRAVE ${ }^{1,2}$, VIVEK VERMA ${ }^{3}$, ROBERT FÖRSTER ${ }^{1,2,4}$, INGMAR SCHLAMPP ${ }^{1,2}$, \\ KATHARINA HEES ${ }^{5,6}$, THOMAS BRUCKNER ${ }^{5}$, TILMAN BOSTEL ${ }^{1}$, \\ RAMI EL SHAFIE ${ }^{1}$, NILS HENRIK NICOLAY ${ }^{1,2,7}$, JÜRGEN DEBUS ${ }^{1,2}$ and HARALD RIEF ${ }^{1,2}$ \\ ${ }^{1}$ Department of Radiation Oncology, University Hospital of Heidelberg, Heidelberg, Germany; \\ ${ }^{2}$ Heidelberg Institute of Radiation Oncology (HIRO), Heidelberg, Germany; \\ ${ }^{3}$ Department of Radiation Oncology, Allegheny General Hospital, Pittsburgh, PA, U.S.A.; \\ ${ }^{4}$ Department of Radiation Oncology, University Hospital Zurich, Zurich, Switzerland; \\ ${ }^{5}$ Department of Medical Biometry, University Hospital of Heidelberg, Heidelberg, Germany; \\ ${ }^{6}$ Department of Statistics, TU Dortmund University, Dortmund, Germany; \\ ${ }^{7}$ Department of Radiation Oncology, University Hospital of Freiburg, Freiburg, Germany
}

\begin{abstract}
Background/Aim: Quality of life (QOL) is becoming increasingly important to appraise the value of a particular oncologic intervention. This was a prespecified secondary analysis of a randomized trial (NCT02832830) of intensity-modulated radiotherapy (IMRT) versus conventional three-dimensional conformal radiotherapy (3DCRT) as part of palliative management of symptomatic spinal metastases. This study examined QOL, fatigue, emotional distress, and late toxicities between patients having received IMRT versus 3DCRT. Materials and Methods: Sixty patients were enrolled in this single-institutional randomized exploratory trial in which all patients received 30 Gy in 10 fractions. The EORTC QLQ-BM22, EORTC QLQ-FA13, and QSC-R10 questionnaires were utilized to evaluate $Q O L$, fatigue, and emotional distress, respectively; endpoints were evaluated at baseline, and at 3, and 6 months. Late (6 months) toxicities were assessed according to the LENT-SOMA criteria. Results: Mean follow-up was 192 days (IQR=77-285). Although QOL was similar between groups, patients in the IMRT arm experienced lower physical $(p=0.011)$ and emotional
\end{abstract}

Correspondence to: Tanja Sprave, MD MBA, University of Heidelberg, Department of Radiation Oncology, Im Neuenheimer Feld 400, 69120 Heidelberg, Germany. Tel: +49 6221568202, Fax: +49 6221565353, e-mail: tanja.sprave@med.uni-heidelberg.de

Key Words: Spinal metastases, quality of life, intensity-modulated radiotherapy, palliative radiotherapy, toxicity.
( $p=0.017)$ fatigue at 6 months. Emotional distress was also lower in IMRT-treated patients after six months $(p=0.039)$. Cohen's effect size confirmed the clinically significant improvement of these findings. Late toxicities occurred infrequently and were similar between arms. Conclusion: This is the first randomized study evaluating QOL between IMRT and 3DCRT to palliate vertebral metastases. IMRT resulted in reduced physical and emotional fatigue as well as emotional distress. IMRT should be further studied for these patients given these outcomes.

Spinal metastases occur in up to $40 \%$ of advanced-stage cancer patients and can be a major cause of quality of life (QOL) and symptomatic deterioration (1). These include pain, immobility, neurological deficits, and pathological fractures; additionally, fatigue (associated with disease and therapy) occurs in over two-thirds of patients and has a major QOL impact (2-4).

Historically, three-dimensional conformal radiotherapy (3DCRT) has been the technique of choice for palliation (5, $6)$. However, advanced technologies such as intensitymodulated radiation therapy (IMRT), often implemented with image guidance, are more conformal and result in lower doses to nearby organs-at-risk (OARs). A number of studies have demonstrated the advantages of IMRT in both curative and palliative settings for various cancers (7-11). A prospective non-randomized study of patients with head and neck cancer found improved QOL in IMRT patients compared to patients treated with 3DCRT (12). However, the 
impact of multi-fraction IMRT on QOL in patients with spine metastases has not been investigated in prospective randomized studies to date. This is important to perform, as QOL is becoming increasingly important to appraise the value of a particular intervention (13-15).

This was a prespecified secondary analysis of a randomized trial of IMRT versus conventional 3DCRT as part of palliative management of symptomatic spinal metastases. This study examined QOL, fatigue, emotional distress, and late toxicity between patients having received IMRT versus 3DCRT.

\section{Materials and Methods}

Trial design and participants. The randomized trial, registered on Clinicaltrials.gov (NCT02832830), was approved by the Heidelberg University Independent Ethics Committee (Number S-238/2016). Details of the study design have been published previously (16). Briefly, a block randomization approach (block size of 6) was used to ensure that both groups were balanced. The primary endpoint of this randomized, single-institutional, pilot trial was 3-month RTinduced toxicity following delivery of $30 \mathrm{~Gy}$ in 10 fractions of image-guided IMRT versus conventional 3DCRT in patients with previously untreated spinal metastases. All patients had an established indication for RT, including pain and/or neurological deficits. The present investigation was a prespecified secondary analysis regarding QOL, emotional distress and late toxicity at 6 months after RT.

Inclusion criteria were ages $18-85$, a Karnofsky performance score $\geq 50$ (ECOG $\leq 2$ ), and ability to provide written informed consent. Exclusion criteria were significant neurological or psychiatric disorders precluding informed consent, receipt of prior RT to the same site, or radiosensitive (multiple myeloma or lymphoma) histologies. Number or location of metastases were not specific inclusion or exclusion criteria, nor was the presence of spinal cord compression.

Assessment of endpoints. Per protocol, QOL, fatigue, and emotional distress were assessed at baseline and at 3 and 6 months after RT. These comprised of the documentation of patient-specific data and the following questionnaires: EORTC QLQ-BM22, EORTC QLQFA13, and QSC-R10.

The QOL endpoint was quantified using the well-validated EORTC QLQ BM22 questionnaire, which is specifically designed for patients with bone metastases. This questionnaire (range $=0-100$ ) comprises 22 items and four scales for the measurement of pain in various body areas (painful sites), pain characteristics (persistent pain, recurrent pain), functional impairment (pain when performing various activities, interference with everyday activities), and psychosocial aspects (family, worries, hope) $(17,18)$.

Fatigue was assessed using the EORTC QLQ FA13 (range=0100) questionnaire. This includes 13 items and five scales for measuring cancer-related fatigue (19), with subscales covering physical, emotional, and cognitive fatigue, along with interference with daily life, and social sequelae.

Emotional distress was evaluated using the QSC-R10 (range $=0$ 50) questionnaire (20). This module is a valid and reliable questionnaire for determining emotional distress and anxiety in cancer patients (21). The questionnaires were filled out by the patients at the study site.

Lastly, late side-effects were captured according to the Late Effects of Normal Tissue - Subjective, Objective, Management and Analytic (LENT-SOMA) criteria.

Radiotherapy. CT simulation was performed with custom immobilization using Aquaplast ${ }^{\circledR}$ (Aquaplast Corporation, Wyckoff, NJ, USA) head masks for cervical spine cases and Wingstep/ Prostep ${ }^{\circledR}$ (Elekta, Stockholm, Sweden) devices for thoracolumbar cases. In addition to OARs (dose constraints for which were per QUANTEC recommendations), the clinical target volume (CTV) was delineated on the planning CT and encompassed the affected vertebral body or the whole sacrum for sacral lesions (22). The planning target volume (PTV) was an isotropic $1 \mathrm{~cm}$ expansion of the CTV and was to be covered by the $90 \%$ isodose line. The prescription dose for both cohorts was 30 Gy in 10 fractions.

The IMRT group received image-guided (mega- or kilo-voltage cone beam computed tomography) RT by means of step-and-shoot IMRT, VMAT (Elekta Versa HD accelerator), or helical TomoTherapy (Accuray Inc., Madison, WI, USA). The 3DCRT cohort was most commonly delivered with two or three anteroposterior $6 \mathrm{MV}$ individually-formed beams. Position verification was applied by weekly kilo-voltage CT and before each fraction by comparing orthogonal portal images with digitally reconstructed radiographs from the planning CT.

Statistical analyses. On account of the explorative character of this study it was not possible to estimate the total number of cases; however, with 30 patients per group, it was possible to detect a standardized effect (Cohen's d) of about 0.8 with $80 \%$ power and a significance level $(\alpha)$ of $5 \%$.

All variables were analyzed descriptively by tabulation of the measures of the empirical distributions. According to the scale level of the variables, means, standard deviations, medians, as well as minimum and maximum (or absolute and relative frequencies) were reported. Additionally, for variables with longitudinal measurements, the time courses of individual patients are summarized by treatment groups. Descriptive $p$-values of the corresponding statistical tests comparing treatment groups were given. The Wilcoxon signed rank test was used to compare differences. Cohen's effect size (ES) was assessed for clinically relevant changes in questionnaire measures ( $<0.3$ low, 0.3-0.7 moderate, $>0.7$ strong differences).

Finally, we compared the groups regarding overall and bone survival using Kaplan-Meier estimates and log-rank tests. All statistical analyses were performed with SAS software v 9.4 (SAS Institute, Cary, NC, USA).

\section{Results}

From November 2016 to May 2017, 60 patients were randomized. No patients were excluded post randomization. Baseline characteristics were balanced between the two treatment arms (Table I, as previously published (23).

Although all but one surviving patients completed all assessments, not all patients survived by the three and sixmonth time periods. Within the first 3 months, 10 patients $(33.3 \%)$ in the IMRT group had died, along with 11 patients 
Table I. Baseline characteristics of randomly assigned participants. Explanation: Others: carcinoma of unknown primary (CUP), gastrointestinal stromal tumor (GIST), melanoma, mesothelioma, pancreatic cancer, renal cancer.

\begin{tabular}{|c|c|c|c|c|c|}
\hline & \multicolumn{2}{|c|}{ IMRT group $n=30$} & \multicolumn{2}{|c|}{ 3DCRT group $n=30$} & \multirow[t]{2}{*}{$p$-Value } \\
\hline & $\mathrm{n}$ & $\%$ & $\mathrm{n}$ & $\%$ & \\
\hline Age (years) & & & & & 0.219 \\
\hline Mean (SD) & $66.1(10.5)$ & & $62.5(11.8)$ & & \\
\hline Karnofsky-Perfomance Status & & & & & 0.283 \\
\hline Mean (SD) & $64.9(9.32)$ & & $61.3(9.7)$ & & \\
\hline Gender & & & & & 0.795 \\
\hline Male & 17 & 56.7 & 16 & 53.3 & \\
\hline Female & 13 & 43.3 & 14 & 46.7 & \\
\hline Weight (kg, SD) & $75.8(14.9)$ & & $76.2(19.4)$ & & 0.929 \\
\hline Height $(\mathrm{cm}, \mathrm{SD})$ & $171.6(8.8)$ & & $172.2(8.6)$ & & 0.790 \\
\hline Body mass index (BMI) & & & & & 0.960 \\
\hline Mean (SD) & $25.7(4.4)$ & & $25.6(5.7)$ & & \\
\hline \multicolumn{6}{|l|}{ Primary site } \\
\hline Lung cancer & 11 & 36.7 & 16 & 53.3 & \\
\hline Breast cancer & 7 & 23.3 & 6 & 20 & \\
\hline Prostate cancer & 6 & 20 & 1 & 3.3 & \\
\hline Other & 6 & 20 & 7 & 23.3 & \\
\hline Localization of metastases & & & & & 0.261 \\
\hline Cervical & 4 & 13.3 & 5 & 16.7 & \\
\hline Thoracic & 15 & 50 & 15 & 50 & \\
\hline Lumbar & 11 & 36.7 & 7 & 23.3 & \\
\hline Sacrum & 0 & 0 & 3 & 10 & \\
\hline Number of metastases & & & & & 0.140 \\
\hline 1 metastasis & 17 & 56.7 & 10 & 33.3 & \\
\hline 2 metastases & 4 & 13.3 & 9 & 30 & \\
\hline 3 metastases & 9 & 30 & 11 & 36.7 & \\
\hline \multicolumn{6}{|l|}{ Distant metastases at baseline } \\
\hline Visceral & 14 & 46.7 & 10 & 33.3 & 0.292 \\
\hline Lung & 7 & 23.3 & 6 & 20 & 0.754 \\
\hline Brain & 4 & 13.3 & 5 & 16.7 & 0.718 \\
\hline Tissue & 5 & 16.7 & 5 & 16.7 & 1.000 \\
\hline Hormonetherapy & 12 & 40 & 6 & 20 & 0.091 \\
\hline Immunotherapy & 4 & 13.3 & 5 & 16.7 & 0.718 \\
\hline Chemotherapy & 14 & 46.7 & 20 & 66.7 & 0.118 \\
\hline Surgery & 18 & 60 & 13 & 43.3 & 0.196 \\
\hline Neurological deficit at baseline & 4 & 13.3 & 3 & 10 & 0.688 \\
\hline Bisphosphonate at baseline & 13 & 43.3 & 7 & 23.3 & 0.100 \\
\hline Orthopedic corset at baseline & 9 & 30 & 10 & 33.3 & 0.781 \\
\hline \multicolumn{6}{|l|}{ Medication at baseline } \\
\hline Sleeping medication & 5 & 16.7 & 2 & 6.7 & 0.228 \\
\hline Psychiatric medication & 9 & 30 & 6 & 20 & 0.371 \\
\hline Opiate & 20 & 66.7 & 17 & 56.7 & 0.426 \\
\hline NSAID & 23 & 76.7 & 19 & 63.3 & 0.260 \\
\hline
\end{tabular}

IMRT: Intensity-modulated radiotherapy; 3DCRT: 3D conformal radiotherapy; NSAID: non-steroidal inflammatory drug; SD: standard deviation.

$(36.7 \%)$ in the 3DCRT arm. Between 3 and 6 months, another 2 patients $(10 \%)$ died due to tumor progression in the IMRT cohort, along with a further 7 patients $(36.8 \%)$ in the 3DCRT arm (Figure 1). The mean follow-up was 192 days (IQR 77285) for both groups.

QOL was evaluated by means of the EORTC QLQ-BM22 module. Therein, there were no significant differences between cohorts in terms of painful sites, pain characteristics, psychosocial aspects or functional impairment (Table II).

Evaluation of fatigue using the EORTC QLQ FA13 module revealed no differences between groups (at either 3 or 6 months) with regard to interference with daily life and social sequelae (Table III). However, after six months, patients in the IMRT arm had significantly lower physical 


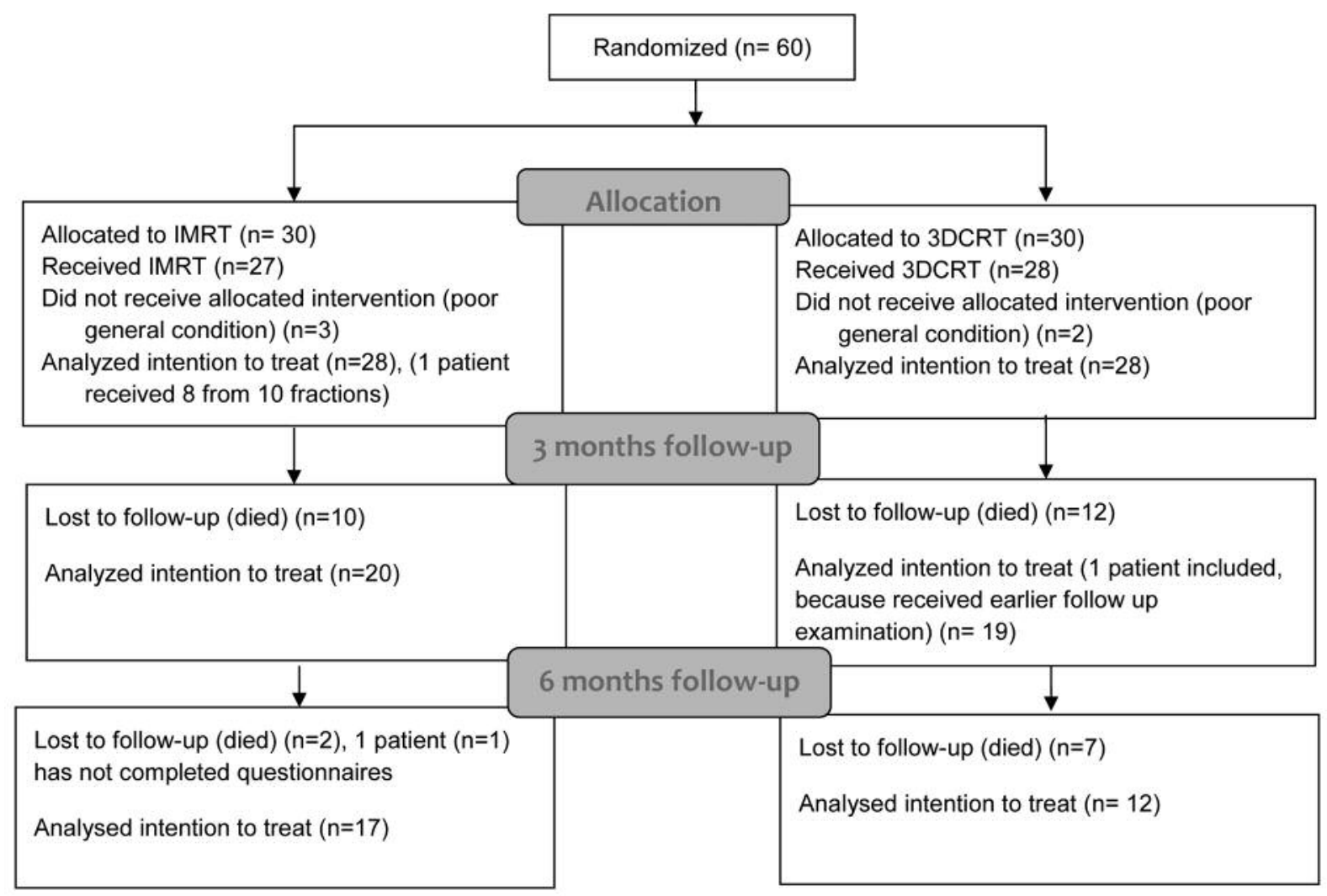

Figure 1. CONSORT diagram of the trial.

$(p=0.011)$ and emotional fatigue $(p=0.017)$. Cohen's ES confirmed the clinically significant improvement in these parameters (ES 1.08) and (ES 1.03), respectively.

Emotional distress, as measured by the QSC-R10 module was similar at three months, but superior in the IMRT group at six months $(p=0.039)$ (Table IV). Cohen's ES (0.93) confirmed these findings as well.

Additionally, late toxicity profiles at 6 months were examined according to LENT-SOMA criteria. The most frequent sideeffects in the IMRT group were grades 1-2 such as dyspnea $(n=3,16.7 \%)$ and parasthesia $(n=2,11.1 \%)$. In contrast, the most frequent side-effects in the 3DCRT group were grades 1-2 esophagitis, diarrhea, radiculitis, myositis, and myalgia $(n=2$, $16.7 \%$ each) (Table V). In total only one participant (5.6\%) in the IMRT arm reported grade 3 radiculopathy. No grade $\geq 4$ adverse events occurred in either group. No significant differences in late toxicity were observed between groups.

\section{Discussion}

Maintaining QOL in patients with advanced malignancies is of paramount importance. QOL impairment occurs not only by disease itself, but also by therapeutic interventions and their sequelae. For instance, patients with painful spinal metastases may suffer from not only neoplastic pain, but also from side effects of interventions and analgesics. Radiotherapy can reduce pain and thus reduce analgesic consumption, which can be reflected in increased QOL profiles (24). Thus, choosing optimal therapy modalities and techniques in the palliative situation is crucial (25).

This is the first randomized study to illustrate the effect of IMRT on reducing physical and emotional fatigue as well as emotional distress.

More than half of patients with advanced tumors suffer from moderate fatigue before commencing radiation therapy (24). To this extent, reduction of further treatment-related fatigue is essential. Herein, the substantial improvement in physical $(p=0.011)$ and emotional fatigue $(p=0.017)$ at 6 months is consistent with other data from our group showing similar improvements in physical fatigue after 6 months with training of paravertebral muscles during RT (26). Although it is theoretically possible that higher conformality decreases damage to normal tissues, which in turn would decrease fatigue, there are few prospective data to confirm this statement. However, dose-fractionation regimens have been shown to be more robustly associated with fatigue (27), and 
Table II. Effects on QOL (EORTC QLQ-BM 22).

Symptom scales

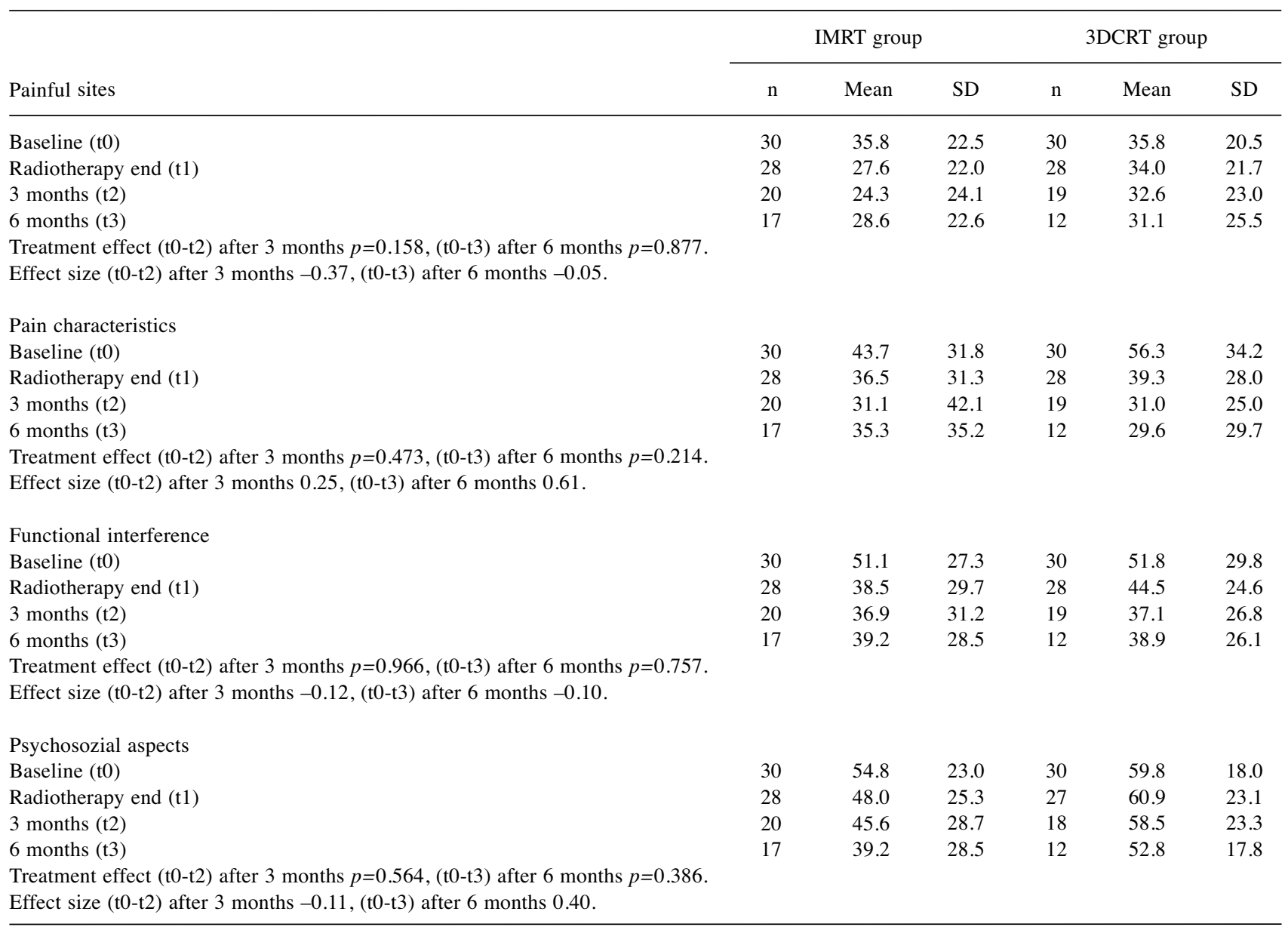

IMRT: Intensity-modulated radiotherapy; 3DCRT: 3D conformal radiotherapy.

the fact that all patients received $30 \mathrm{~Gy}$ in 10 fractions would imply that fatigue may be more equivalent between cohorts than numeric/statistical values suggest.

Furthermore, psychosocial distress, depression, and anxiety are particularly prevalent in advanced disease stages (28), with clinical depression and anxiety ranging from 20-39\% (29). Oncological patients undergoing radiation therapy are at high risk for these mental health disorders; over half of patients may be on antidepressants or anxiolytics before the start of RT (30). To this extent, it is noteworthy that emotional distress was lower in the IMRT group at six months $(p=0.039)$, which are in concord with results by Rief and colleagues (26).

There were no significant QOL differences between both groups, which are consistent with established data from our group (26). Nevertheless, it is intuitive that, with similar dose-fractionation schemes in both cohorts, the QOL corresponding to painful sites, pain characteristics, and functional interference would be statistically similar. As with several of the aforementioned measures, however, this parameter greatly depends on the precise nature of patientphysician communication as well as a host of several other factors that could confound conclusions in this and any other QOL or patient-reported outcome analysis (31).

Lastly, regarding the equipoise of late toxicities between arms (but with more significant differences in acute events (23) implies that even acute toxicities have lasting and measurable influences on QOL in these patients. These issues must be further probed, which also have implications on the increasing use of stereotactic radiotherapy for vertebral metastases.

Despite the prospective randomized nature of this study with a low drop-out rate, there are several limitations, in addition to 
Table III. Effects on fatigue according to EORTC QLQ-FA 13.

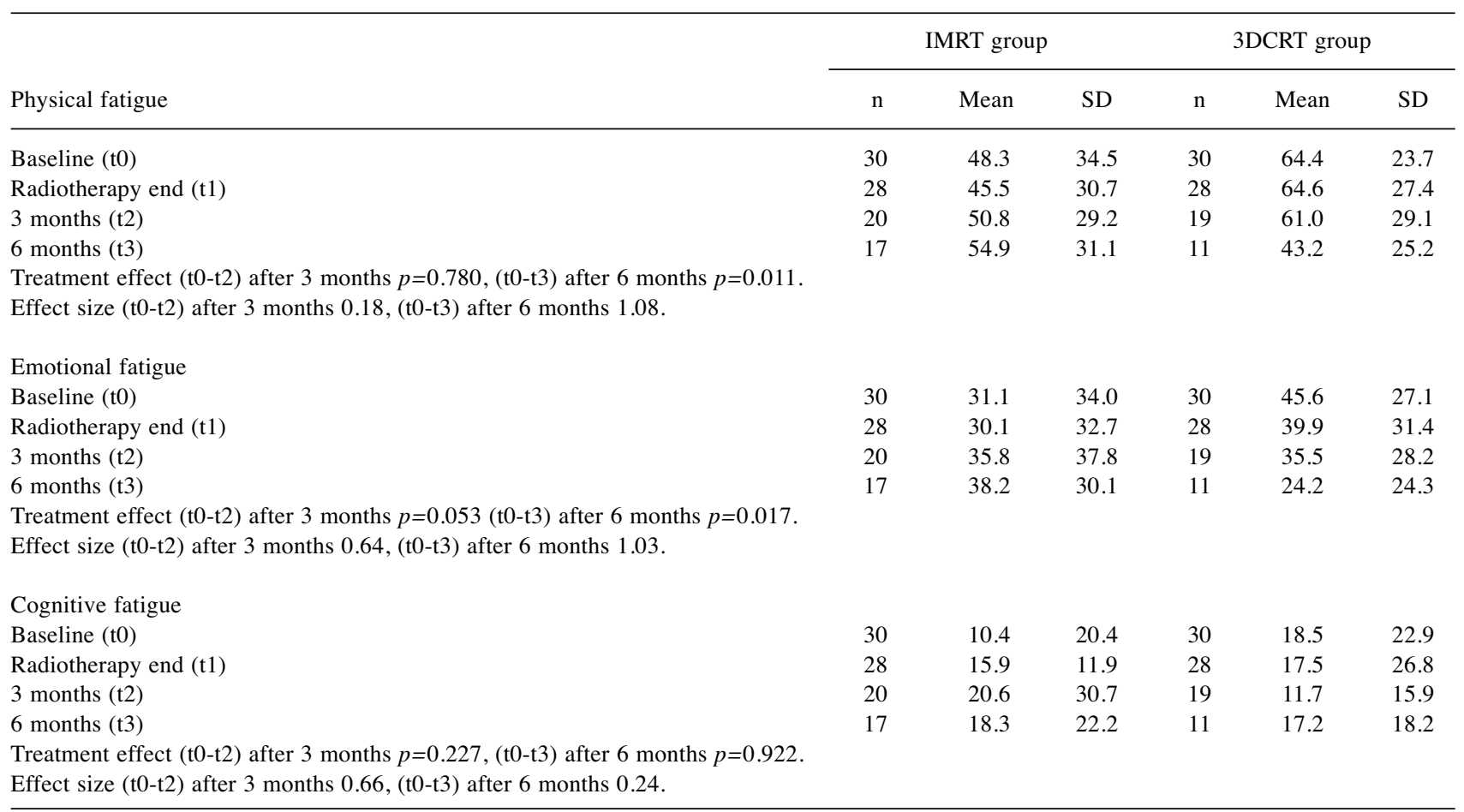

IMRT: Intensity modulated radiotherapy; 3CRT: 3D conformal radiotherapy.

Table IV. Effects on emotional distress according to the FBK-R10 questionnaire.

\begin{tabular}{|c|c|c|c|c|c|c|}
\hline \multirow[b]{2}{*}{ FBK R10 } & \multicolumn{3}{|c|}{ IMRT group } & \multicolumn{3}{|c|}{ 3DCRT group } \\
\hline & $\mathrm{n}$ & Mean & SD & $\mathrm{n}$ & Mean & SD \\
\hline Baseline (t0) & 30 & 20.3 & 9.1 & 30 & 22.5 & 9.6 \\
\hline Radiotherapy end (t1) & 28 & 15.2 & 9.1 & 28 & 21.0 & 9.5 \\
\hline 3 months (t2) & 20 & 15.7 & 11.4 & 19 & 16.9 & 10.1 \\
\hline 6 months (t3) & 17 & 21.2 & 11.1 & 12 & 13.5 & 8.9 \\
\hline
\end{tabular}

IMRT: Intensity modulated radiotherapy; 3DCRT: 3D conformal radiotherapy.

those presented above such as the small sample size, diversity in primary disease (and degree of control thereof), and lack of formal power calculations owing to the explorative nature. Moreover, because all patients had advanced cancer, $60 \%$ of the IMRT patients and $40 \%$ of the 3DCRT group were lost to follow-up from progressive disease and/or death. Finally, as described elsewhere (15), it is imperative to mention that no study evaluating QOL or patient-reported outcomes can account for the innumerable factors that influence these variables, including prior therapy, baseline characteristics, social support, comorbidities, experience at the radiation facility, and nature of follow-up. As a result, further data are highly encouraged to validate the conclusion made herein.

\section{Conclusion}

This is the first randomized study evaluating QOL between IMRT and 3DCRT to palliate vertebral metastases. IMRT results in reduced physical and emotional fatigue along with emotional distress. Although IMRT should be further studied for these patients given these outcomes, larger randomized trials are necessary to confirm these findings. 
Table V. Toxicity profile at 6 months after radiotherapy in both groups.

\begin{tabular}{|c|c|c|c|c|c|c|}
\hline \multirow[b]{2}{*}{ Grade } & \multirow[t]{2}{*}{$\begin{array}{c}\text { All } \\
\mathrm{n}(\%)\end{array}$} & \multirow{2}{*}{$\begin{array}{c}\text { IMRT group } \\
\mathrm{n}(\%) \\
1-2\end{array}$} & \multicolumn{3}{|c|}{$\begin{array}{l}\text { 3DCRT group } \\
\mathrm{n}(\%)\end{array}$} & \multirow[t]{2}{*}{$p$-Value } \\
\hline & & & $\geq 3-4$ & $1-2$ & $\geq 3-4$ & \\
\hline Xerostomia & $1(3.3)$ & 0 & 0 & $1(8.3)$ & 0 & 0.213 \\
\hline Dysphagia & $1(3.3)$ & 0 & 0 & $1(8.3)$ & 0 & 0.213 \\
\hline Esophagitis & $2(6.7)$ & 0 & 0 & $2(16.7)$ & 0 & 0.073 \\
\hline Vomiting & 0 & 0 & 0 & 0 & 0 & \\
\hline Nausea & $2(3.3)$ & 0 & 0 & $2(6.6)$ & 0 & 0.200 \\
\hline Diarrhea & $2(6.7)$ & 0 & 0 & $2(16.7)$ & 0 & 0.073 \\
\hline Dyspnea & $4(13.3)$ & $3(16.7)$ & 0 & $1(8.3)$ & 0 & 0.677 \\
\hline Pneumonitis & 0 & 0 & 0 & 0 & 0 & \\
\hline Myelitis & $1(3.3)$ & 0 & 0 & $1(8.3)$ & 0 & 0.200 \\
\hline Parasthesia & $2(6.7)$ & $2(11.1)$ & 0 & 0 & 0 & 0.232 \\
\hline Brachial plexopathy & $3(10.0)$ & $1(5.6)$ & 0 & $2(16.7)$ & 0 & 0.320 \\
\hline Radiculitis & $4(13.3)$ & $1(5.6)$ & $1(5.6)$ & $2(16.7)$ & 0 & 0.517 \\
\hline Peripheral motoric neuropathy & $1(3.3)$ & $1(5.6)$ & 0 & 0 & 0 & 0.406 \\
\hline Dermatitis & $1(3.3)$ & 0 & 0 & $1(8.3)$ & 0 & 0.213 \\
\hline Myalgia & $3(10.0)$ & $1(5.6)$ & 0 & $2(16.6)$ & 0 & 0.431 \\
\hline Myositis & $3(10.0)$ & $1(5.6)$ & 0 & $2(16.7)$ & 0 & 0.152 \\
\hline
\end{tabular}

IMRT: Intensity-modulated radiotherapy; 3DCRT: 3D conformal radiotherapy.

\section{Conflicts of Interest}

The Authors declare that they have no competing interests.

\section{Acknowledgements}

The sponsors of the study had no role in study design, data analysis, data interpretation and wording of the report. The corresponding author (HR) had full access to the entire data of the study and had the final responsibility regarding the decision to submit for publication.

\section{References}

1 Wong DA, Fornasier VL and MacNab I: Spinal metastases: the obvious, the occult, and the impostors. Spine 15: 1-4, 1990.

2 Smets EM, Garssen B, Schuster-Uitterhoeve AL and de Haes JC: Fatigue in cancer patients. Brit J Cancer 68: 220-224, 1993.

3 Curt GA: The impact of fatigue on patients with cancer: overview of FATIGUE 1 and 2. The Oncologist 5: 9-12, 2000.

4 Ahlberg K, Ekman T, Gaston-Johansson F and Mock V: Assessment and management of cancer-related fatigue in adults. Lancet 362: 640-650, 2003.

5 Sze WM, Shelley M, Held I and Mason M: Palliation of metastatic bone pain: single fraction versus multifraction radiotherapy - a systematic review of the randomised trials. Cochrane Database Syst Rev 2: CD004721, 2004.

6 McQuay HJ, Collins SL, Carroll D and Moore RA: Radiotherapy for the palliation of painful bone metastases. Cochrane Database Syst Rev 2: Cd001793, 2000.

7 Wortel RC, Incrocci L, Pos FJ, Lebesque JV, Witte MG, van der Heide UA, van Herk M and Heemsbergen WD: Acute toxicity after image-guided intensity modulated radiation therapy compared to 3D conformal radiation therapy in prostate cancer patients. Int J Radiat Oncol Biol Phys 91: 737$744,2015$.

8 Grills IS, Yan D, Martinez AA, Vicini FA, Wong JW and Kestin LL: Potential for reduced toxicity and dose escalation in the treatment of inoperable non-small-cell lung cancer: a comparison of intensity-modulated radiation therapy (IMRT), 3D conformal radiation, and elective nodal irradiation. Int $\mathrm{J}$ Radiat Oncol Biol Phys 57: 875-890, 2003.

9 Sujenthiran A, Nossiter J, Charman SC, Parry M, Dasgupta P, van der Meulen J, Cathcart PJ, Clarke NW, Payne H and Aggarwal A: National population-based study comparing treatment-related toxicity in men who received intensity modulated versus 3-dimensional conformal radical radiation therapy for prostate cancer. Int J Radiat Oncol Biol Phys 99: 1253-1260, 2017.

10 van Beek KM, Kaanders JH, Janssens GO, Takes RP, Span PN and Verhoef CG: Effectiveness and toxicity of hypofractionated high-dose intensity-modulated radiotherapy versus 2- and 3dimensional radiotherapy in incurable head and neck cancer. Head Neck 38: E1264-1270, 2016.

11 Rief H, Habermehl D, Schubert K, Debus J and Combs SE: Time evaluation of image-guided radiotherapy in patients with spinal bone metastases. A single-center study. Strahlentherapie und Onkologie : Organ der Deutschen Rontgengesellschaft [et al] 190: 287-292, 2014.

12 Vergeer MR, Doornaert PA, Rietveld DH, Leemans CR, Slotman BJ and Langendijk JA: Intensity-modulated radiotherapy reduces radiation-induced morbidity and improves health-related quality of life: results of a nonrandomized prospective study using a standardized follow-up program. Int J Radiat Oncol Biol Phys 74: 1-8, 2009. 
13 Schnipper LE, Davidson NE, Wollins DS, Blayney DW, Dicker AP, Ganz PA, Hoverman JR, Langdon R, Lyman GH, Meropol NJ Mulvey T, Newcomer L, Peppercorn J, Polite B, Raghavan D, Rossi G, Saltz L, Schrag D, Smith TJ, Yu PP, Hudis CA, Vose JM and Schilsky RL : Updating the American Society of clinical oncology value framework: revisions and reflections in response to comments received. J Clin Oncol 34: 2925-2934, 2016.

14 Verma V, Simone CB, 2nd and Mishra MV: Quality of Life and Patient-Reported Outcomes Following Proton Radiation Therapy: A Systematic Review. J Natl Cancer Inst 110, 2018. doi: $10.1093 /$ jnci/djx208

15 Verma V, Mishra MV and Mehta MP: A systematic review of the cost and cost-effectiveness studies of proton radiotherapy. Cancer 122: 1483-1501, 2016.

16 Meyerhof E, Sprave T, Welte SE, Nicolay NH, Forster R, Bostel T, Bruckner T, Schlampp I, Debus J and Rief H: Radiationinduced toxicity after image-guided and intensity-modulated radiotherapy versus external beam radiotherapy for patients with spinal bone metastases (IRON-1): a study protocol for a randomized controlled pilot trial. Trials 18: 98, 2017.

17 Chow E, Nguyen J, Zhang L, Tseng LM, Hou MF, Fairchild A, Vassiliou V, Jesus-Garcia R, Alm El-Din MA, Kumar A, Forges F, Chie WC and Bottomley A: International field testing of the reliability and validity of the EORTC QLQ-BM22 module to assess health-related quality of life in patients with bone metastases. Cancer 118: 1457-1465, 2012.

18 Chow E, Hird A, Velikova G, Johnson C, Dewolf L, Bezjak A, Wu J, Shafiq J, Sezer O, Kardamakis D Linden Yv, Ma B, Castro M, Arnalot PF, Ahmedzai S, Clemons M, Hoskin P, Yee A, Brundage $\mathrm{M}$ and Bottomley A: The European organisation for research and treatment of cancer quality of life questionnaire for patients with bone metastases: the EORTC QLQ-BM22. Eur J Cancer 45: 1146-1152, 2009.

19 Weis J, Arraras JI, Conroy T, Efficace F, Fleissner C, Gorog A, Hammerlid E, Holzner B, Jones L, Lanceley, A Singer S, Wirtz $\mathrm{M}$, Flechtner $\mathrm{H}$ and Bottomley A: Development of an EORTC quality of life phase III module measuring cancer-related fatigue (EORTC QLQ-FA13). Psychooncology 22: 1002-1007, 2013.

20 Book K, Marten-Mittag B, Henrich G, Dinkel A, Scheddel P, Sehlen S, Haimerl W, Schulte T, Britzelmeir I and Herschbach $\mathrm{P}$ : Distress screening in oncology-evaluation of the Questionnaire on Distress in Cancer Patients-short form (QSCR10) in a German sample. Psychooncology 20: 287-293, 2011.

21 Escalante CP: Treatment of cancer-related fatigue: an update. Support Care Cancer 11: 79-83, 2003.

22 Marks LB, Yorke ED, Jackson A, Ten Haken RK, Constine LS, Eisbruch A, Bentzen SM, Nam J and Deasy JO: Use of normal tissue complication probability models in the clinic. Int J Radiat Oncol Biol Phys 76: 10-19, 2010.

23 Sprave T, Verma V, Förster R, Schlampp I, Bruckner T, Bostel T, Welte SE, Tonndorf-Martini E, El Shafie R, Nicolay NH, Debus $\mathrm{J}$ and Rief H:Radiation-induced acute toxicities after image-guided intensity-modulated radiotherapy versus threedimensional conformal radiotherapy for patients with spinal metastases (IRON-1 trial): First results of a randomized controlled trial. Strahlenther Onkol, 2018. doi: 10.1007/s00066018-1333-z. [Epub ahead of print]
24 Zeng L, Chow E, Bedard G, Zhang L, Fairchild A, Vassiliou V, Alm El-Din MA, Jesus-Garcia R, Kumar A, Forges F, Tseng LM, Hou MF, Chie WC and Bottomley A: Quality of life after palliative radiation therapy for patients with painful bone metastases: results of an international study validating the EORTC QLQ-BM22. Int J Radiat Oncol Biol Phys 84: e337-342, 2012.

25 Raman S, Ding K, Chow E, Meyer RM, Nabid A, Chabot P, Coulombe G, Ahmed S, Kuk J and Dar AR: A prospective study validating the EORTC QLQ-BM22 bone metastases module in patients with painful bone metastases undergoing palliative radiotherapy. Radiother Oncol 119: 208-212, 2016.

26 Rief H, Akbar M, Keller M, Omlor G, Welzel T, Bruckner T, Rieken S, Hafner MF, Schlampp I, Gioules A and Debus J: Quality of life and fatigue of patients with spinal bone metastases under combined treatment with resistance training and radiation therapy- a randomized pilot trial. Radiat Oncol 9: 151, 2014.

27 Shaitelman SF, Schlembach PJ, Arzu I, Ballo M, Bloom ES, Buchholz D, Chronowski GM, Dvorak T, Grade E, Hoffman KE Kelly P, Ludwig M, Perkins GH, Reed V, Shah S, Stauder MC, Strom EA, Tereffe W, Woodward WA, Ensor J, Baumann D, Thompson AM, Amaya D, Davis T, Guerra W, Hamblin L, Hortobagyi G, Hunt KK, Buchholz TA and Smith BD: Acute and short-term toxic effects of conventionally fractionated vs. hypofractionated whole-breast irradiation: A randomized clinical trial. JAMA Oncol 1: 931-941, 2015.

28 Nieder C, Dalhaug A, Haukland E and Engljähringer K: Patientreported symptom burden, rate of completion of palliative radiotherapy and 30-day mortality in two groups of cancer patients managed with or without additional care by a multidisciplinary palliative care team. Anticancer Res 38: 2271-2275, 2018.

29 Mitchell AJ, Chan M, Bhatti H, Halton M, Grassi L, Johansen $\mathrm{C}$ and Meader $\mathrm{N}$ : Prevalence of depression, anxiety, and adjustment disorder in oncological, haematological, and palliative-care settings: a meta-analysis of 94 interview-based studies. Lancet Oncol 12: 160-174, 2011.

30 Holtzman AL, Pereira DB and Yeung AR: Implementation of depression and anxiety screening in patients undergoing radiotherapy. BMJ Open Qual 7: e000034, 2018.

31 Nieder C and Kämpe TA: Contribution of patient-reported symptoms before palliative radiotherapy to development of multivariable prognostic models. Anticancer Res 38: 1705-1709, 2018.
Received May 31, 2018

Revised July 5, 2018

Accepted July 9, 2018 